\title{
Gas Permeation Properties of Asymmetric Polyimide Membranes Made by Ion-beam Irradiation
}

Received in revised form 6 April 2005, accepted 6 April 2005

\author{
A. Sannomiya ${ }^{1}$, M. Iwase ${ }^{2}$, S. Nagaoka ${ }^{3}$, Y. Suzuki ${ }^{4}$, M. Iwaki ${ }^{5}$ \& H. Kawakami ${ }^{6 *}$ \\ ${ }^{1,2,3 \& 6}$ Department of Applied Chemistry, Tokyo Metropolitan University, Hachioji, Tokyo 192-0397, Japan \\ ${ }^{4 \& 5}$ The Institute of Physical and Chemical Research, 2-1 Hirosawa, Wako, Saitama 351-0198, Japan
}

\begin{abstract}
In this study, the gas permeance and selectivity of the asymmetric polyimide membrane with skin layer carbonized by $\mathrm{He}$ ions irradiation were measured using a high vacuum apparatus with a Baratron absolute pressure gauge at $76 \mathrm{cmHg}$ and $35^{\circ} \mathrm{C}$. Particularly, we focused on the effects of the depth profile of the energy loss for the irradiating $\mathrm{He}$ ions in the skin layer on the gas permeation properties of the asymmetric membranes. Irradiation depth is gauged through the energy loss profile of the irradiating ions. The nature of the carbonised layer was investigated using AFM and ATR-FTIR. We demonstrated that the $\mathrm{PO}_{2}$ of the $\mathrm{He}^{+}$-irradiated membranes increased with the skin layer thickness and that the depth of the irradiating ions in the skin layer had a significant influence on the gas permeability and selectivity of the asymmetric membrane.
\end{abstract}

Keywords : Asymmetric polyimide membrane, ion-beam irradiation, He ion, gas permeation property, gas separation

\subsection{INTRODUCTION}

Polymer membranes are considered an effective technology for the separation of gaseous mixtures due to their high separation efficiency, low operating costs, and simple operation. The development of novel polymer membranes with even higher gas permeabilities and selectivities has received much attention [1]. However, many studies of the structure/permeability relationships of polymer membranes have led to trade-off correlations between the gas permeability and selectivity, which have become a major problem in realizing a gas separation process using polymer materials [2]. Therefore, an important objective for the gas separation membrane is the development of new polymer membranes combining high gas permeability and selectivity.

We reported the gas permeability through an asymmetric polyimide membrane with a thin and defect-free skin layer prepared by a dry-wet phase inversion process [3-7]. We succeeded in preparing an asymmetric polyimide membrane with an ultrathin and defect-free skin layer $(10 \mathrm{~nm})$ having a significantly high gas permeance. Additionally, we have reported the preparation and the gas permeation properties of novel organic-inorganic hybrid membranes, which exhibits an asymmetric

\footnotetext{
* Correspondence to: H. Kawakami (tel: +81-426-77-1111 (ext. 4972), fax: +81-426-77-2821, e-mail: kawakami-hiroyoshi@c.metrou.ac.jp)
} 
structure consisting of a carbonized skin layer and a polymeric porous substructure [8]. Recently, great interest has been focused on the syntheses of inorganic membranes for gas separation. Particularly, a carbon molecular sieve (CMS) membrane, which is synthesized by the pyrolysis of a polymer, is considered as one of the candidates for a gas separation membrane $[9,10]$. However, CMS membranes are very brittle and fragile. Additionally, they require more careful handling, and preparation of a thin CMS membrane is very difficult because of its poor mechanical properties. Therefore, the gas permeances of.CMS membranes were not very high.

On the other hand, a novel asymmetric polyimide membrane with an ultrathin and defect-free carbonized skin layer as an organic-inorganic hybrid membrane was prepared by the modification of the skin surface using ion-beam irradiation. It is well known that ion-beam irradiation can directly modify the surface of a membrane and that the polymer surface irradiated under high ion fluence is carbonized $[11,12]$. The asymmetric membrane with the carbonized skin layer is characterized by its toughness and good mechanical properties, and we considered that the ultrathin and defect-free carbonized skin layer would realize both high gas permeability and selectivity. The interesting result reported in a previous paper was that the profile of the energy loss for the irradiating ions in the skin layer had a significant influence on the gas permeability and selectivity of the asymmetric membrane.

The objective of this study is to elucidate the gas permeation properties of the asymmetric polyimide membranes with the ultrathin and defect-free carbonized skin layer. Particularly, we focused on the depth effects of the irradiating ions on the gas permeation properties of the asymmetric polyimide membranes, because the energy loss profile of ions penetrating into a polymer matrix strongly depends on the depth of the ions. The asymmetric membranes with different skin layer thicknesses were prepared by the dry-wet phase separation process. The gas permeances of the asymmetric polyimide membranes irradiated with $50 \mathrm{keV} \mathrm{He}{ }^{+}$at a fluence of $3 \times 10^{15} \mathrm{ions} / \mathrm{cm}^{2}$ have been measured using a high vacuum apparatus with a Baratron absolute pressure gauge at $76 \mathrm{cmHg}$. Additionally, the angular-dependent measurements of the irradiating ions were carried out to investigate the energy loss effects of ions on the gas permeation properties of the irradiated asymmetric membranes in detail, because the angle between the irradiating ion and the membrane is known to significantly influence the depth profile of the energy loss for the irradiating ions.

\subsection{EXPERIMENTAL SECTION}

\subsection{Materials}

2,2'-Bis(3,4-dicarboxyphenyl)hexafluoropropane dianhydride (6FDA) was purchased from the Clariant Co. (Shizuoka, Japan) and purified by sublimation, prior to use. The diamine monomer was 2,2'-bis(4-aminophenyl)hexafluoropropane (6FAP), which was purchased from the Central Glass Co., (Saitama, Japan) and recrystallized twice in ethanol prior to use.

The polyimide, 6FDA-6FAP, was synthesized by chemical imidization of the poly(amic acid) precursors as reported in the literatures $[13,14]$. The structures of 6FDA-6FAP are shown in Figure 1. The synthesized 6FDA-6FAP had an Mw of $3.2 \times 10^{5}$ with a polydispersity index of 2.1 .

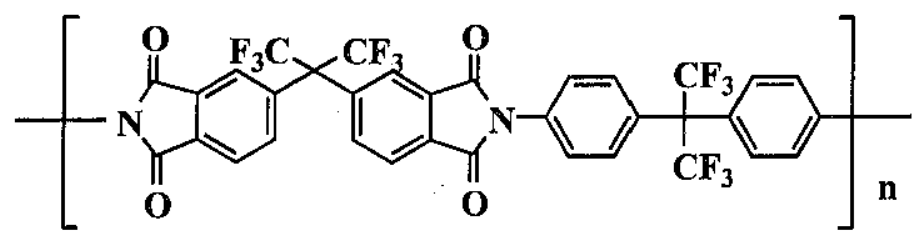

Figure 1 Chemical structure of 6FDA-6FAP polyimide 


\subsection{Preparation of Asymmetric Polyimide Membranes}

To investigate the effects of the skin layer thickness on the gas permeation properties of the asymmetric polyimide membrane, membranes with different skin layer, approximately $100 \mathrm{~nm}$ and $1 \mathrm{~mm}$, were prepared by a dry/wet phase inversion process $[3,4,15]$. The polyimide solutions were made from 15-17 wt $\%$ polyimide, $60 \mathrm{wt} \%$ methylene chloride, 14-18 wt $\% 1,1,2$-trichloroethane, and 6-9.5wt $\%$ 1-butanol. After being filtered and degassed, the polyimide solutions were casted on a glass plate with a doctor-blade and then air-dried for $15 \mathrm{~s}$ at room temperature. After evaporation, the membranes were coagulated in methanol, washed for $12 \mathrm{hr}$, air-dried for $24 \mathrm{hr}$ at room temperature, and finally dried in a vacuum oven at $150^{\circ} \mathrm{C}$ for $15 \mathrm{hr}$ to remove all of the residual solvents.

\subsection{Ion-beam Irradiation on Asymmetric Membranes}

Ion-beam irradiation is a physico-chemical surface-modification process resulting from the impingement of a high-energy ion beam (Riken ion implanter, Riken, Saitama, Japan) [16]. The ion depth through the top skin layer is regulated by changing the ion specie and its energy. In this study, ion irradiation was performed on polyimide membranes and $\mathrm{He}^{+}$was used. Ion irradiation was carried out on a $2 \times 2 \mathrm{~cm}^{2}$ surface area at an energy of $50 \mathrm{keV}$ at a fluence of $3 \times 10^{15}$ ions $/ \mathrm{cm}^{2}$.

\subsection{Surface Characterization of Asymmetric Membranes}

The surface morphology of the asymmetric polyimide membranes was visualized by an atomic force microscope (AFM, SPI3700, Seiko, Tokyo, Japan) in air at room temperature. Standard $\mathrm{Si}_{3} \mathrm{~N}_{4}$ cantilevers (SN-AF01, Seiko, Tokyo, Japan), with a spring constant of $0.021 \mathrm{~N} / \mathrm{m}$, were used and operated in the non-contact mode. The surface was continuously imaged in the feedback mode with a scan area of $500 \times 500 \mathrm{~nm}$ and at a constant scan speed of $2 \mathrm{~Hz}$. The surface roughness parameter of the membranes was denoted by $R_{a}$, which is an arithmetic mean of departure of the roughness profile from the mean line.

The surface change in the ion-irradiated polyimide membrane was measured by Fourier transform infrared spectroscopy combined with attenuated total reflectance (FTIR-ATR Nexus 470, Nicolet, Tokyo, Japan) and laser Raman spectroscopy (LabRam, Jobin Yvon, Tokyo, Japan). A square Ge crystal in an ATP objective was used, and sixty-four scans of $2 \mathrm{~cm}^{-1}$ resolution were averaged to achieve a sufficient signal-to-noise ratio. The Raman spectra was observed using an He-Ne laser of $632.817 \mathrm{~nm}$.

\subsection{Gas Permeation Measurements}

Gas permeances of carbon dioxide, oxygen, and nitrogen were measured with a high vacuum apparatus (Rika Seiki, Inc., K-315-H, Tokyo, Japan). The gas permeation measurements of the membranes were carried out at $35^{\circ} \mathrm{C}$ and $76 \mathrm{cmHg}$. The apparent skin layer thickness of the asymmetric polyimide membranes was calculated from:

$$
L=\frac{P}{Q}
$$

where $L[\mathrm{~cm}]$ is the apparent skin layer thickness, $P\left[\mathrm{~cm}^{3}(\mathrm{STP}) \mathrm{cm} /\left(\mathrm{cm}^{2} \mathrm{sec} \mathrm{cmHg}\right)\right]$ is the gas permeability coefficient measured from a dense polyimide flat membrane, and $Q\left[\mathrm{~cm}^{3}(\mathrm{STP}) /\left(\mathrm{cm}^{2}\right.\right.$ $\mathrm{sec} \mathrm{cmHg}$ )] is the gas permeance of the asymmetric polyimide membranes. $L$ was determined from the oxygen permeability coefficient. 


\subsection{RESULTS AND DISCUSSION}

\subsection{Surface Characteristics of Asymmetric Membranes}

Figure 2 shows the AFM image of the top surface of an asymmetric polyimide membrane in a threedimensional form over an area of $500 \times 500 \mathrm{~nm}$. The surfaces of the $\mathrm{He}^{+}$-irradiated polyimide membranes were significantly smoother than that determined for an asymmetric polyimide membrane before ion irradiation as a control membrane. These results were similar to those reported in the previous papers [8]. However, there was no difference in the surface morphology between the membranes irradiated at take-off angles of $90^{\circ}$ and $30^{\circ}$.

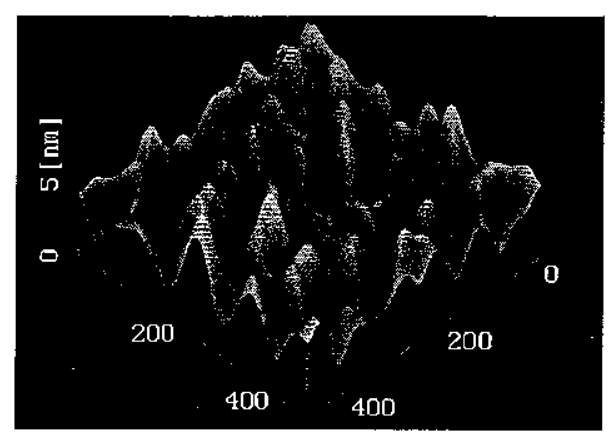

$\mathrm{Ra}=1.1 \mathrm{~nm}$

(a)

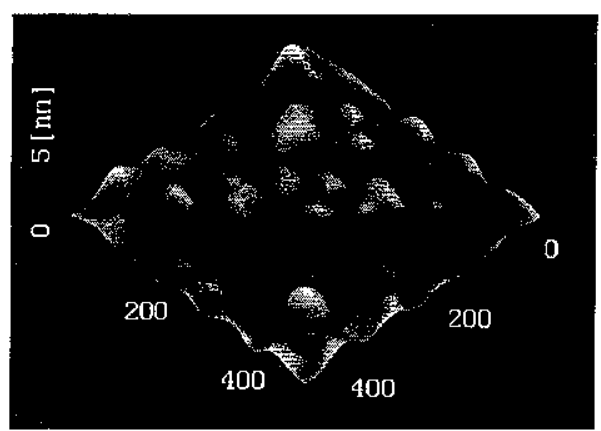

$\mathrm{Ra}=0.27 \mathrm{~nm}$

(b)

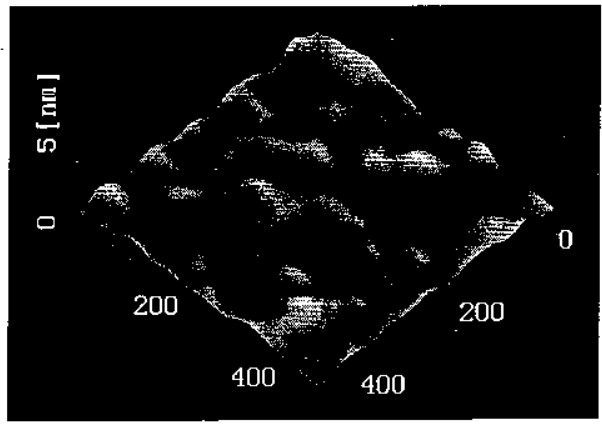

$\mathrm{Ra}=0.24 \mathrm{~nm}$

(c)

Figure 2 AFM images of top surface of asymmetric 6FDA-6FAP membranes. A scan area was $500 \times 500 \mathrm{~nm}$ : (a) control, (b) $\mathrm{He}^{+}$-irradiation at $3 \times 10^{15}$ ions $/ \mathrm{cm}^{2}$ and at take-off angle of $90^{\circ}$, and (c) $\mathrm{He}^{+}$-irradiation at $3 \times 10^{15}$ ions $/ \mathrm{cm}^{2}$ and at take-off angle of $30^{\circ}$

Figure 3 shows the ATR-FTIR spectra of the asymmetric polyimide membranes irradiated at takeoff angles of $90^{\circ}$ and $30^{\circ}$. As shown in a previous paper, there was a significant difference in the absorbance between the membrane before ion irradiation as the control membrane and the irradiated membranes, and the absorbance intensities of the carbonyl $\left(1720 \mathrm{~cm}^{-1}\right), \mathrm{CF}_{3}\left(1200-1250 \mathrm{~cm}^{-1}\right)$, imide $\left(1376 \mathrm{~cm}^{-1}\right)$, and aromatic $\left(1500 \mathrm{~cm}^{-1}\right)$ groups were significantly reduced. Simultaneously, a 


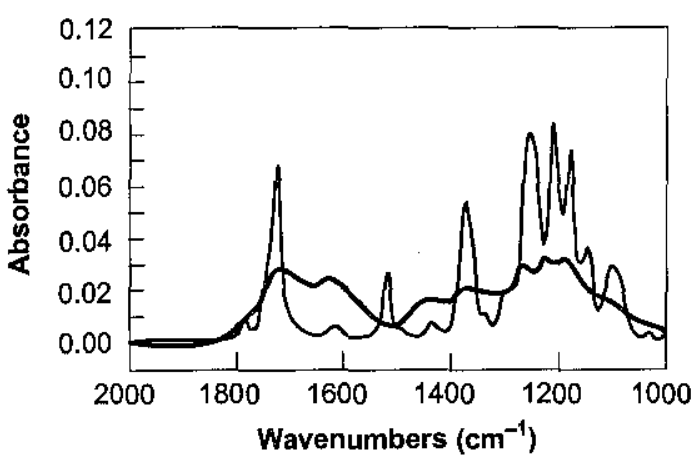

(a)

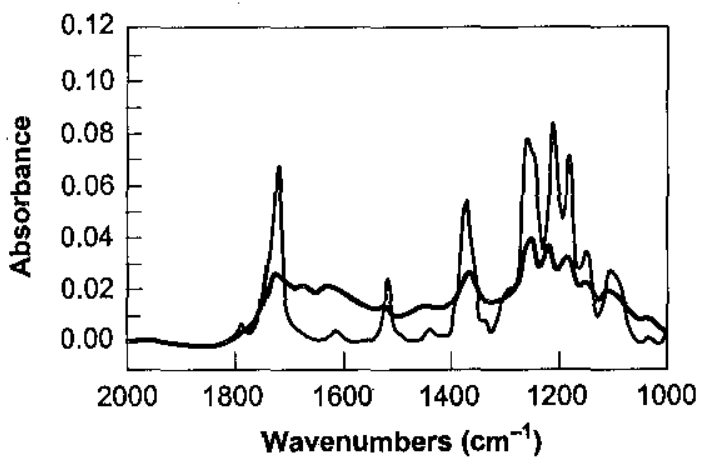

(b)

Figure 3 ATR-FTIR spectra of asymmetric 6FDA-6FAP membranes: (a) (-) control, (-) $\mathrm{He}^{+}$-irradiation at $3 \times 10^{15}$ ions $/ \mathrm{cm}^{2}$ and at take-off angle of $90^{\circ} ;(\mathrm{b})(-)$ control, $\left(^{-}\right) \mathrm{He}^{+}$-irradiation at $3 \times 10^{15}$ ions/ $\mathrm{cm}^{2}$ and at take-off angle of $30^{\circ}$

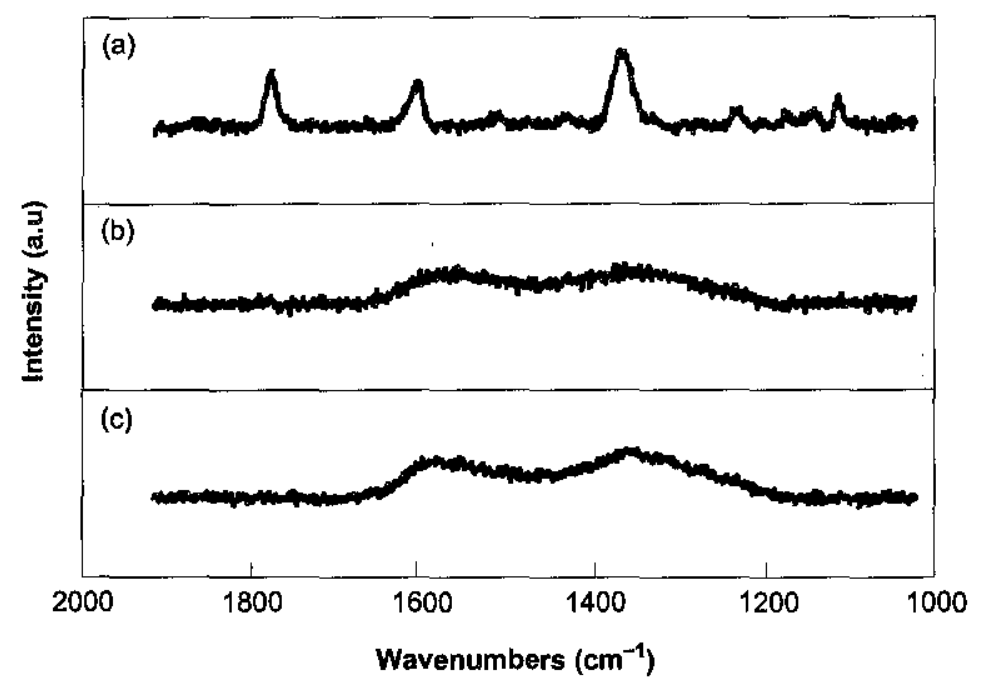

Figure 4 Raman spectra of asymmetric 6FDA-6FAP membranes: (a) control; (b) $\mathrm{He}^{+}$-irradiation at $3 \times 10^{15}$ ions $/ \mathrm{cm}^{2}$ and at take-off angle of $90^{\circ}$; (c) $\mathrm{He}^{+}$-irradiation at $3 \times 10^{15}$ ions $/ \mathrm{cm}^{2}$ and at take-off angle of $30^{\circ}$

broad band appears in the region of $1550-1650 \mathrm{~cm}^{-1}$ based on the formation of graphite-like and carbon-rich amorphous structures. However, the difference in the $\mathrm{He}^{+}$-irradiated membranes at angles of $90^{\circ}$ and $30^{\circ}$ is not shown, although ion-beam irradiation induced changes in the chemical structure of the polyimide surface.

Figure 4 shows the Raman spectra of the asymmetric polyimide membranes irradiated at take-off angles of $90^{\circ}$ and $30^{\circ}$. After the irradiation of a $50 \mathrm{keV} \mathrm{He}{ }^{+}$at a fluence of $3 \times 10^{15}$ ions $/ \mathrm{cm}^{2}$, the peaks at $1240,1380,1620$, and $1780 \mathrm{~cm}^{-1}$ corresponding to $\mathrm{C}-\mathrm{F}_{3}, \mathrm{C}-\mathrm{N}$, and $\mathrm{C}=\mathrm{C}$ in the aromatic ring, and $\mathrm{C}=\mathrm{O}$, respectively, disappeared, as shown in a previous paper [8]. However, two broad peaks on the irradiated polyimide surface appeared at around 1360 and $1580 \mathrm{~cm}^{-1}$. These peaks 
correspond, respectively, to the well-known D and $\mathrm{G}$ broad bands of disordered graphitic materials indicating that the surface on the membrane changed to a carbon-enriched material. Particularly, the $\mathrm{D}$ and $\mathrm{G}$ broad band peaks for the membrane irradiated at an angle of $30^{\circ}$ were slightly larger than those of the membrane at $90^{\circ}$, indicating that the surface on the former would change to a more carbon-enriched material when compared with that on the latter.

\subsection{Gas Permeation Properties of Asymmetric Membranes}

Irradiating ions penetrating into a polymer membrane lose energy by several interactions between the ions and the polymer. The energy loss mechanism is considered as electronic energy loss, which involves the process of electronic excitation and ionization of the atoms in the polymers, as the exchanges of electrons between incident ions and the atoms in the polymer, and as nuclear energy loss, which involves atomic collisions between the incident ions and the atoms in the polymer [17]. In a previous paper, we demonstrated that the gas selectivity of the $\mathrm{He}^{+}$-irradiated membrane increased with an increase in the ion fluence and that the profile of the energy loss for the irradiating ions in the skin layer had a significant influence on the gas permeability and selectivity of the asymmetric membrane [8]. As is apparent from the depth simulation of the energy loss mechanism in Figure 5, the relative contribution of the electronic energy loss becomes greater for a thinner surface skin layer and that of nuclear energy loss becomes greater for a thicker layer. We considered that the polyimide structure in the ion-irradiated surface layer would be closely correlated to the amount of nuclear energy loss and that the structure eventually determined the free volume and the free volume distribution formed in the membrane. Previous results indicated that the gas permeability and selectivity were dramatically improved for the $\mathrm{He}^{+}$-irradiated membranes with a thicker surface skin layer [8]. We carried out angular-dependent measurements by $\mathrm{He}$ ions to investigate the depth profile of the energy loss mechanism on the gas permeation properties of the irradiated asymmetric polyimide membranes in detail, because the incident angle is known to significantly influence the depth profile of the energy loss for the irradiating ions, as shown in Figure 5. The depth profiles of the energy loss for $\mathrm{He}^{+}$irradiation at $50 \mathrm{keV}$ in the asymmetric polyimide membrane were estimated using a wellestablished Monte Carlo simulation method (TRIM code). The mean projected ranges of the He ions

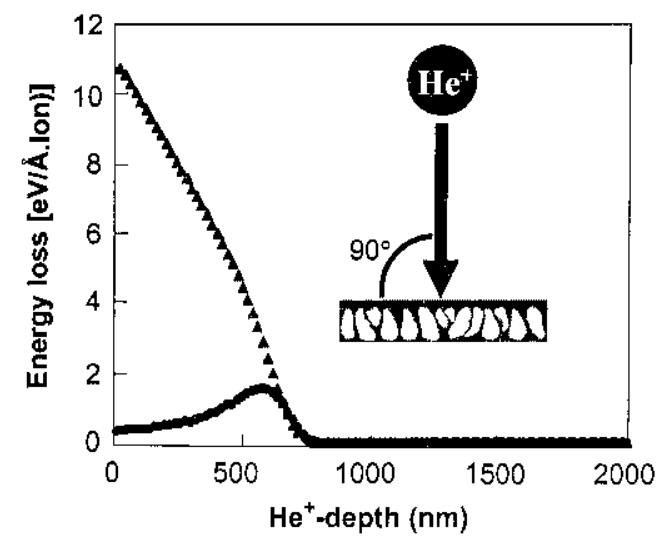

(a)

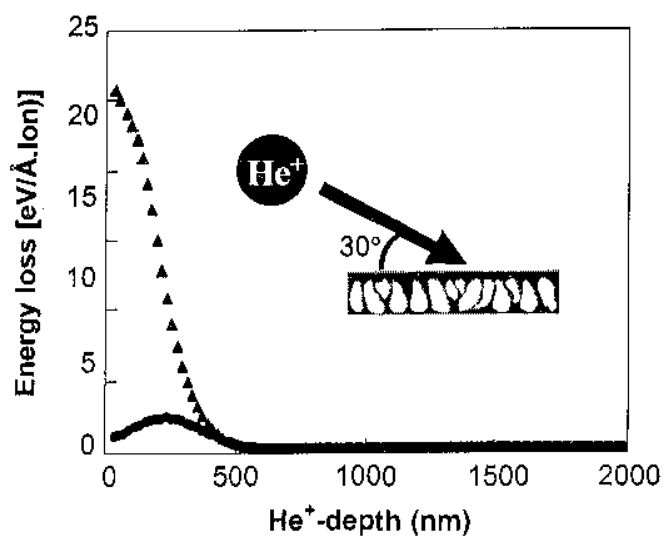

(b)

Figure 5 Relationship between $\mathrm{He}^{+}$-depth and energy loss in 6FDA-6FAP membrane: (a) take-off angle of $90^{\circ}$, (b) take-off angle of $30^{\circ}$ 
for take-off angles of $90^{\circ}$ and $30^{\circ}$ in the membrane was 860 and $700 \mathrm{~nm}$, respectively, and the energy loss was relatively flat over a large portion of the depth range. The electronic energy loss was greater than the nuclear energy loss, and the maximum values of nuclear energy loss for angles of $90^{\circ}$ and $30^{\circ}$ were approximately 580 and $250 \mathrm{~nm}$, respectively.

The results of the gas permeability coefficient and selectivity of the asymmetric polyimide membranes for $\mathrm{O}_{2}$ and $\mathrm{N}_{2}$ at $35^{\circ} \mathrm{C}$ and $76 \mathrm{cmHg}$ are shown in Table $1 . \mathrm{He}^{+}$irradiation was carried out on the polyimide surface at $50 \mathrm{keV}$ with a fluence of $3 \times 10^{15} \mathrm{ions} / \mathrm{cm}^{2}$. The asymmetric polyimide membrane before ion irradiation as the control membrane indicated an oxygen permeability coefficient $\left(\mathrm{PO}_{2}\right)$ of $13 \times 10^{-10}\left[\mathrm{~cm}^{3}(\mathrm{STP}) \mathrm{cm} /\left(\mathrm{cm}^{2} \mathrm{sec} \mathrm{cmHg}\right)\right]$, and the apparent skin layer thicknesses of the asymmetric polyimide membranes were calculated from the oxygen permeability coefficient. The gas selectivities of all the asymmetric membranes were greater than those $\left(\mathrm{O}_{2} / \mathrm{N}_{2}=4.5\right)$ of a dense membrane, which indicates that the permeation of the asymmetric membrane is predominantly carried out by a solution-diffusion mechanism and that the surface skin layer is essentially defect-free.

Table 1 Effect of $\mathrm{He}^{+}$incident angle on gas permeability coefficient and selectivity of $\mathrm{He}^{+}$-irradiated asymmetric $6 \mathrm{FDA}-6 \mathrm{FAP}$ polyimide membranes at $35^{\circ} \mathrm{C}$ and $76 \mathrm{cmHg}$

\begin{tabular}{|c|c|c|c|}
\hline Thickness (nm) & Angle ( $\left.{ }^{\circ}\right)$ & $\mathrm{PO}_{2}$ & $\mathrm{PO}_{2} / \mathrm{PN}_{2}$ \\
\hline Virgin (dense) ${ }^{a}$ & - & 13 & 4.5 \\
\hline 130 & 90 & 1.9 & 7.5 \\
\hline 290 & 90 & 3.0 & 7.7 \\
\hline 850 & 90 & 7.8 & 6.6 \\
\hline 150 & 30 & 1.1 & 5.4 \\
\hline 330 & 30 & 2.1 & 7.2 \\
\hline 770 & 30 & 2.3 & 6.2 \\
\hline
\end{tabular}

a Thickness $=53 \mu \mathrm{m}, \mathrm{P}: 10^{-10}\left[\mathrm{~cm}^{3}(\mathrm{STP}) \mathrm{cm} /\left(\mathrm{cm}^{2}, \mathrm{sec}, \mathrm{cmHg}\right)\right]$

Both the gas permeability coefficient and selectivity of the asymmetric polyimide membranes strongly depended on the apparent skin layer thickness, as shown in Table 1. The asymmetric membranes irradiated at an angle of $90^{\circ}$ showed a larger $\mathrm{PO}_{2}$ when compared with the membrane at an angle of $30^{\circ}$, which may be due to the fact that the surface on the membrane irradiated by angle of $30^{\circ}$ changed to a more carbon-enriched material, as apparent from Raman spectra results or from the amount of energy loss as shown in Figure 5. However, the $\mathrm{PO}_{2}$ of both the $\mathrm{He}^{+}$-irradiated asymmetric membranes increased with the skin layer thickness. Particularly, the $\mathrm{PO}_{2}$ of the asymmetric membranes irradiated at an angle of $90^{\circ}$ strongly depended on the thickness. In contrast, the gas $\mathrm{PO}_{2} / \mathrm{PN}_{2}$ of the asymmetric membranes showed the maximum values. It should be noted that the $\mathrm{PO}_{2} / \mathrm{PN}_{2}$ in the asymmetric membrane with 290- and 330-nm thicknesses resulted in 171 and $160 \%$ increases, respectively, when compared with that of the asymmetric membrane before ion irradiation. We considered that the polyimide structure in the ion-irradiated surface layer would be closely correlated to the amount of energy loss produced by unclear stopping, which had a significant influence on the gas permeability and selectivity of the asymmetric membrane.

Figures 6 shows the apparent skin layer thickness-dependence of $\mathrm{PO}_{2}$ for the asymmetric polyimide membranes irradiated at a take-off angle of $90^{\circ}$. It was clear that there was a good relationship between the $\mathrm{PO}_{2}$ and the skin layer thickness. The $\mathrm{PO}_{2}$ increased with an increase in the skin layer 


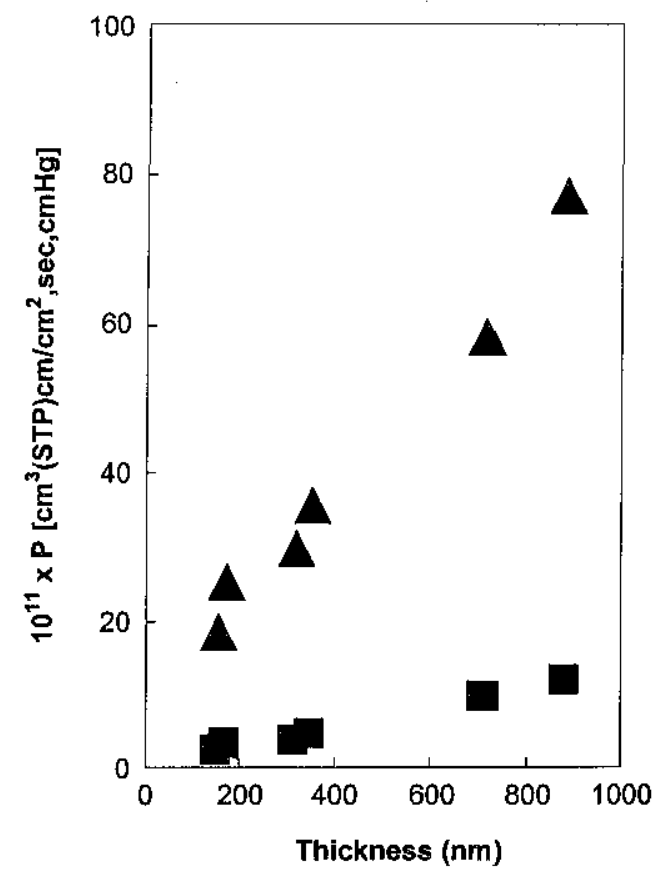

Figure 6 Relationship between apparent skin layer thickness and gas permeability coefficient at $35^{\circ} \mathrm{C}$ and $76 \mathrm{cmHg}$ in asymmetric 6 FDA-6FAP membrane made by $\mathrm{He}^{+}$-irradiation at $3 \times 10^{15}$ ions/ $\mathrm{cm}^{2}$ and at take-off angle of $90^{\circ}:(\mathbf{\Delta}) \mathrm{O}_{2} ;(\mathbf{\square}) \mathrm{N}_{2}$

thickness. The thickness-dependence of $\mathrm{PO}_{2}$ for the asymmetric polyimide membranes irradiated at an angle of $30^{\circ}$ was also similar to that of the membranes at $90^{\circ}$ (data not shown).

Figures 7 shows the $\mathrm{CO}_{2}$ pressure-dependence of the $\mathrm{PCO}_{2}$ for the asymmetric polyimide membranes irradiated at take-off angles of $90^{\circ}$ and $30^{\circ}$. The $\mathrm{PCO}_{2}$ for the asymmetric polyimide membrane before ion irradiation as control slightly decreased with the increasing $\mathrm{CO}_{2}$ pressure in the range from 0.1 to $5 \mathrm{~atm}$, which indicated that the $\mathrm{CO}_{2}$ permeation behavior of the membrane was in accordance with that of the dual mode transport model [18]. In contrast, the $\mathrm{PCO}_{2}$ for the $\mathrm{He}^{+}$irradiated asymmetric polyimide membrane was independent of $\mathrm{CO}_{2}$ pressure. It is well known that the gas sorption and diffusion at a Langmuir site defined by the dual mode transport model strongly depend on the amount of the frozen free volume in the glass polymer. We believe that the amount in the asymmetric polyimide membrane irradiated by He ions was significantly reduced due to a change in polyimide structure induced by the ion irradiation so that the $\mathrm{PCO}_{2}$ of the membrane did not depend on the $\mathrm{CO}_{2}$ pressure.

\subsection{CONCLUSIONS}

In this study, we investigated the gas permeation properties of asymmetric polyimide membranes with an ultrathin and defect-free carbonized skin layer and clarified the depth effects of the irradiating ions on the gas permeation properties of the asymmetric polyimide membranes. The obtained results have led to some interesting conclusions for the gas permeance and selectivity of the ion-irradiated asymmetric polyimide membranes. One interesting conclusion is that the $\mathrm{PO}_{2}$ of the $\mathrm{He}^{+}$-irradiated 


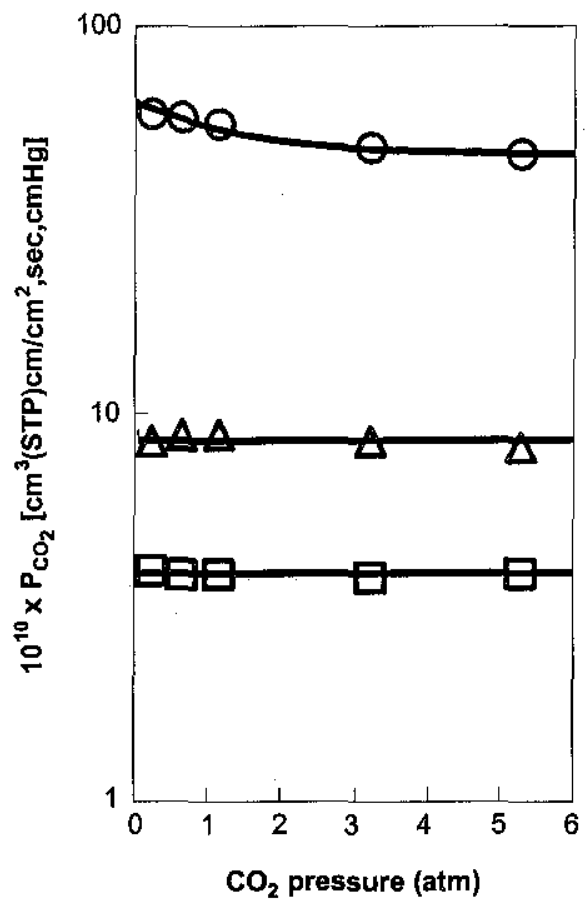

Figure 7 Effect of $\mathrm{CO}_{2}$ pressure on $\mathrm{CO}_{2}$ permeability coefficient in asymmetric 6FDA-6FAP membranes at $35^{\circ} \mathrm{C} ;(O)$ asymmetric 6 FDA-6FAP membrane as control; $(\triangle)$ asymmetric 6 FDA-6FAP membrane made by $\mathrm{He}^{+}$-irradiation at $3 \times 10^{15}$ ions $/ \mathrm{cm}^{2}$ and at take-off angle of $90^{\circ}$, and the apparent skin layer thickness is $220 \mathrm{~nm}$; () asymmetric 6 FDA-6FAP membrane made by $\mathrm{He}^{+}$-irradiation at $3 \times 10^{15}$ ions/ $\mathrm{cm}^{2}$ and at take-off angle of $30^{\circ}$, and the apparent skin layer thickness is $150 \mathrm{~nm}$

membranes increased with the skin layer thickness. Another interesting conclusion is that the correlation between the $\mathrm{PO}_{2} / \mathrm{PN}_{2}$ and the skin layer thickness for the asymmetric membranes showed the maximum values. We consider that the depth of the irradiating ions in the skin layer has a significant influence on the gas permeability and selectivity of the asymmetric membrane and that ion irradiation would be one of the important membrane fabrication techniques for realizing high gas permeability and selectivity.

\section{ACKNOWLEDGEMENTS}

This work was partially supported by the Ministry of Education, Culture, Sports, Science and Technology.

\section{REFERENCES}

[1] Thran, A., G. Kroll, and F. Faupel. 1999. Correlation Between Fractional Free Volume and Diffusivity of Gas Molecules in Glassy Polymers. J. Polym. Sci., Poly, Phys. Ed. 37: 33443358. 
[2] Dai, Y., M. D. Guiver, G. P. Robertson, Y. S. Kang, and K. J. Lee. 2003. Enhancement in the Gas Permeabilities of Novel Polysulfones with Pendant 4-Trimethylsilyl- $\alpha$-hydroxylbenzyl Substituents. Macromolecules. 36: 6807-9816.

[3] Kawakami, H., M. Mikawa, and S. Nagaoka. 1996. Gas Permeability and Selectivity Through Asymmetric Polyimide Membranes. J. Appl. Polym. Sci. 62: 965-971.

[4] Kawakami H., M. Mikawa, and S. Nagaoka. 1988. Gas Transport Properties of Asymmetric Polyimide Membrane with an Ultrathin Surface Skin Layer. Macromolecules. 31: 6636-6638.

[5] Niwa, M., H. Kawakami, S. Nagaoka, T. Kanamori, and T. Shinbo. 2000. Fabrication of an Asymmetric Polyimide Hollow Fiber with a Defect-Free Surface Skin Layer. J. Membr. Sci. 171:253-261.

[6] Niwa, M., H. Kawakami, T. Kanamori, T. Shinbo, and S. Nagaoka. 2001. Gas Separation of Asymmetric 6FDA Polyimide Membrane with Oriented Surface Skin Layer. Macromolecules. 34: 9039-9044.

[7] Niwa, M., H. Kawakami, T. Kanamori, T. Shinbo, A. Kaito, and S. Nagaoka. 2004. Surface Orientation Effect of Asymmetric Polyimide Hollow Fibers on Their Gas Transport Properties. J. Membr. Sci. 230: 141-152.

[8] Iwase, M., A. Sannomiya, S. Nagaoka, Y. Suzuki, M. Iwaki, and H. Kawakami. 2004. Gas Permeation Properties of Asymmetric Polyimide Membranes with Partially Carbonized Skin Layer. Macromolecules. 37: 6892-6897.

[9] Suda, H., and K. Haraya, 1997. Gas Permeation Through Micropores of Carbon Molecular Sieve Membranes Derived from Kapton Polyimide. J. Phys. Chem. B. 101: 3988-3994.

[10] Singh-Ghosal, A., and W. J. Koros. 2000. Air Separation Properties of Flat Sheet Homogeneous Pyrolytic Carbon Membranes. J. Membr. Sci. 174: 177-188.

[11] Ektessabi, A. M, and S. Hakamata. 2000. XPS Study of Ion Beam Modified Polyimide Films. Thin Solid Films. 621: 377-378.

[12] Svorcik, V., E. Arenholz, V. Rybka, and V. Hnatowicz. 1997. AFM Surface Morphology Investigation of Ion Beam Modified Polyimide. Nucl. Instr. and Meth. in Phys. Res. B. 122: 663-667.

[13] Kawakami, H., J. Anzai, and S. Nagaoka. 1995. Gas Transport Properties of Soluble Aromatic Polyimides with Sulfone Diamine Moieties. J. Appl. Polym. Sci. 57: 789-795.

[14] Kawakami, H., M. Mikawa, and S. Nagaoka. 1996. Gas Transport Properties in Thermally Cured Aromatic Polyimide Membranes. J. Membr. Sci. 118: 223-230.

[15] Pinnau, I., J. Wind, and K-V. Peinemann. 1990. Ultrathin Multicomponent Poly(ether sulfone) Membranes for Gas Separation Made by Dry/Wet Phase Inversion. Ind. Eng. Chem. Res. 29: 2028-2032.

[16] Suzuki, Y., M. Kusakabe, and M. Iwaki. 1994. Wettability Control of Polystyrene by Ion Implantation. Nucl. Instr. and Meth. in Phys. Res. B. 91: 584-587.

[17] Xu, X., and M. R. Colernan. 1997. Atomic Force Microscopy Images of Ion-implanted 6FDApMDA Polyimide Films. J. Appl. Poly. Sci. 66: 459-469.

[18] Aitken, C. L., W. J. Koros, and D. R. Paul. 1992. Gas Transport Properties of Biphenol Polysulfones. Macromolecules. 25: 3651-3658. 